\title{
Review on Sludge Drying Process and Dryer in Solar Energy
}

\author{
Xiaojuan An ${ }^{1}$, Weijun Liu ${ }^{2}$ \\ ${ }^{1}$ College of Mechanical Engineering, Shanghai University of Engineering Science, Shanghai, China \\ ${ }^{2}$ Energy and Environmental Engineering Institute, Shanghai University of Engineering Science, Shanghai, China
}

\section{Email address:}

anjuan325@126.com (Xiaojuan An),1wj1119@139.com (Weijun Liu)

\section{To cite this article:}

Xiaojuan An, Weijun Liu. Review on Sludge Drying Process and Dryer in Solar Energy. American Journal of Energy Engineering. Vol. 5, No. 5, 2017, pp. 34-38. doi: 10.11648/j.ajee.20170505.12

Received: October 20, 2017; Accepted: November 17, 2017; Published: December 7, 2017

\begin{abstract}
The objective of this work is to give the fundamental information that should be known about solar sludge drying. The solar sludge drying process and characteristics are presented. Based on some researchers' theoretical analysis and experimental results, the main influence factors of sludge drying process are air temperature and humidity, drying air flow rate, intensity of solar radiation, sludge thickness and drying ways. Some innovative developed solar sludge drying systems are exposed in this review, such as the use of waste flue gas heat/sun capable system. Finally author put forward a new way of solar heat pipe-greenhouse drying system.
\end{abstract}

Keywords: Solar Dryer, Sludge Disposal, Dehydration, Drying Process

\section{Introduction}

The rapid increase of sewage sludge has caused people's life inconvenience and seriously polluted the environment. Each year the amount of sludge production is higher than the sewage sludge disposal in recent years in China. According to the statistics, China, European Union and United States have become the countries and regions of the large amount of sewage sludge production, such as 9.18 million tons sludge in 2009 in China, in 20101.17 million tons sludge in EU and 8 million tons sludge in USA [1-2]. The adverse impacts also have been paid world-wide attention with the rapid increasing of sewage sludge. The sludge is usually applied to soil improvement, incineration and landfill disposal, in USA and Japan, percentage for three major application fields are $39 \%$ \& $75 \%, 20 \% \& 25 \%$ and $41 \% \& 0 \%$. The untreated sludge with high moisture, large volume, which causes many problems such as transportation inconvenience, combustion difficulties and so on. Hence, it is necessary to dehydration of the sludge. Mechanical dehydration is mainly separation and filtration. But the water content of the mechanical dehydration sludge is very high and still up to $70 \%$ or $80 \%$. After removing the major water content from the sludge by the drying process of percolating or vaporizing, which can meet the stability requirement of sludge. The development and improvement of various sludge treatment techniques by solar energy are urgent since the drying process of sludge is high energy consumption.

\section{Drying Principle of Sludge by Solar Energy}

\subsection{The Sludge Drying Characteristic}

The sludge drying process can be defined three stages, as is shown in Figure 1.

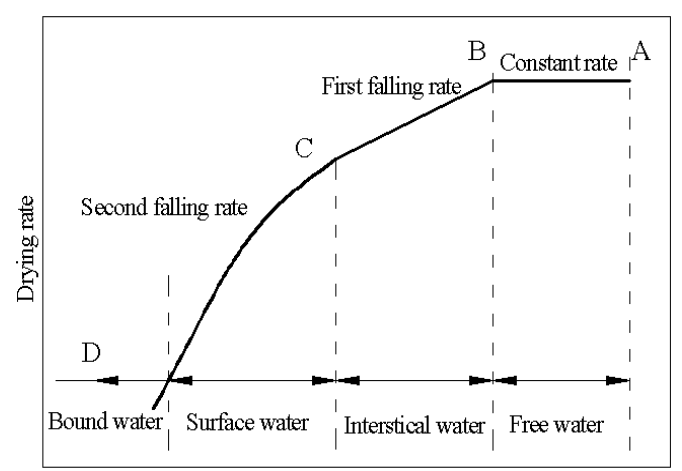

Figure 1. Sludge drying curve. 
Section $\mathrm{AB}$ is the constant drying phase, the rate about water from the material internal to the surface diffusion is as the same as the sludge surface evaporation rate, therefore, the material surface temperature remains constant, and the drying rate also keep a certain value. In this process, the free water was removed. The curve $\mathrm{BC}$ is defined as the first falling rate phase, the sludge internal moisture diffusion rate is far lower than the surface evaporation rate, this deceleration phase lost water which is mainly the sludge of interstitial water. The curve $\mathrm{CD}$, as the second deceleration phase, the moisture in the form of steam spreads to the surface of the sludge. As the drying process continues, the drying rate gradually reduced. Tao observed the inexistence of the constant drying rate during drying of municipal sewage sludge in their experimental labor. They reported this observation due to the utilization, before applying drying process of the mechanical dewatering which removes all the free water [3]. In the last phase, with the drying rate arriving to the lowest, sludge drying can meet the condition of equilibrium moisture content, the drying process is completely over. At this stage, where bound water is removed and equilibrium moisture is reached. The form changes of the sludge begin to contract and then crack from the sludge drying beginning to end.

\subsection{The Drying Process by Solar Energy}

Solar drying technology refers to wet materials absorb the solar energy, or using solar power to heat the air directly, then transfer the heat and mass between the hot air and material. Material after absorbing heat, the surface water evaporated, spreads into the air. As the drying, material internal moisture migration gradually get to the material surface. Eventually reaches the final moisture content. Therefore, the drying process is a process of heat and material exchange.

\section{Research Present Situation of Main Influence Factors of Sludge Drying Process}

In the process of solar drying for sludge, there are many factors which affect the drying rate of sludge. Zheng Zonghe [4] studied the air temperature and flow rate on the role of sludge drying rate, Yuan Jun [5], Li Aimin [6] had a further study on the sludge morphology affect water separation properties. Xiang Yi, Liu Jianzhong [7], through exposure to solar dryers, studied the influence of the intensity of solar radiation on the sludge drying characteristic. It is concluded that when the intensity of solar radiation is much stronger, at the same time, the final moisture content of the sludge is much less, the test results as shown in Figure 2.

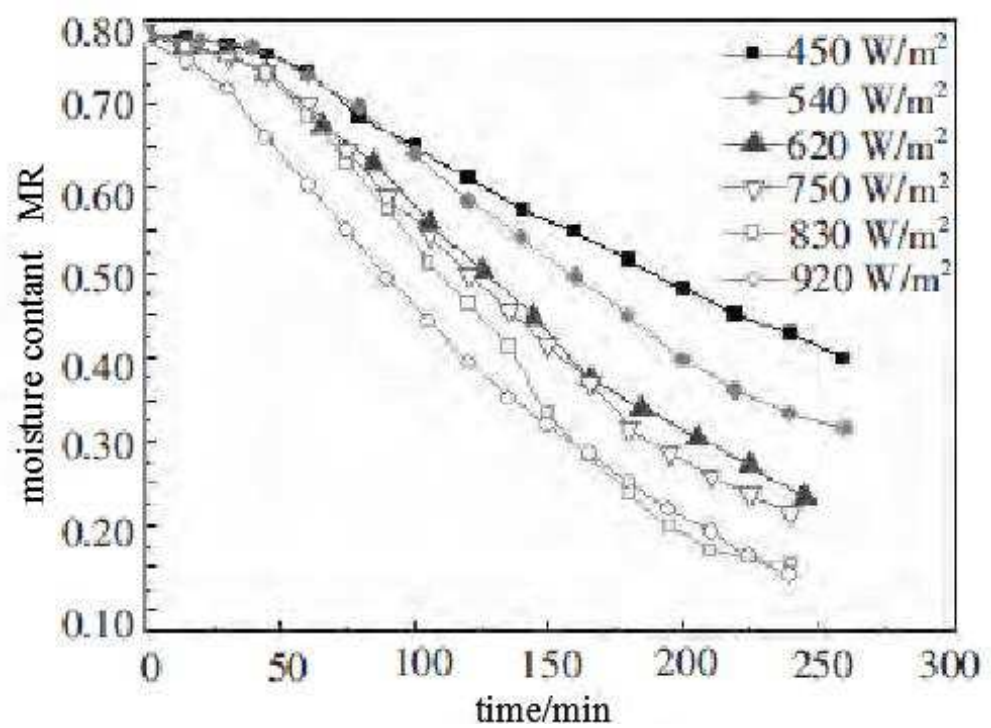

Figure 2. Changes of water content of sludge under different solar radiation intensity in the exposed solar drying system.

It seems obvious that the sludge drying rate with radiation intensity $920 \mathrm{~W} / \mathrm{m}^{2}$ is higher than $620 \mathrm{~W} / \mathrm{m}^{2}$. The radiation intensity is directly related to the drying rate of the sludge. Zhao Lei [8] without auxiliary heat device studied the main parameters changes of the sludge in solar conservatory. It is concluded that temperature and humidity in the solar greenhouse are the main factors having effect on drying rate and there is no obvious regularity between the change of the drying rate and moisture content. Lei Haiyan [9]-[11] through home-made mixed solar dryers, had an experimental research on solar sludge drying. The results show that the sludge deformation, temperature, velocity and solar radiation intensity are the main factors influencing the sludge drying process. The applications of drying are widely found in the literature review such as solar food drying. However, the application of this source of energy to dry sludge is still a subject of intensive studies, such as works published by Seginer and Bux [12] Besides variability of the applied operation conditions, the solar drying characteristics also depend on the climatic conditions, in particular: the solar 
radiation, temperature and velocity of the air. Having studied the influences of different factors in the drying process, especially air temperature and surface drying rate have great effect on sludge drying. Reyes A et al [13], and Léonard A et al [14], concluded that the drying rate is related to the air temperature and velocity. With the same condition, the lower velocity which can have a greater effect on the drying rate of the sludge. Zhang Yunyue [15], by using two different drying devices, solar greenhouses and ventilation cabinets, conducted experiments on the drying of solar sludge. The natural ventilation in summer (rain from time to time), and the sludge was spread out on the floor in $25 \mathrm{~cm}$-lavers in solar greenhouse. Six days later, the moisture content was reduced from 90 percent to about 34 percent. Therefore, it is concluded that: (1) Using solar energy to dry sludge, each kilogram of sludge energy consumption reduction can save about 21MJ; (2) With the same weather conditions, the main drying process was completed within 3 days of the ventilator (water quantity reduced by about $40 \%$ ). It shows that the solar drying is not as well as the ventilators', but the moisture content of the dryers is about 8 percent higher than the condition under the solar greenhouse; (3) The rate of sludge drying in different thicknesses is also varied (even in the same dry condition). The finished sludge drying time with $15 \mathrm{~mm}$ thickness is more than one day of $20 \mathrm{~mm}$ ' (it drops to 37.5 percent and the rate of drying drops significantly). Yin Lijie [16], conducted experiments and simulations on the drying of pure solar sludge in winter. It was concluded that temperature were the main factors affecting the drying of the sludge, if velocity increasing by $1 \mathrm{~m} / \mathrm{s}$, and the drying rate increased by $2.2 \% \sim 13.4 \%$. With increasing $1{ }^{\circ} \mathrm{C}$, the drying rate got up $138.5 \% \sim 287.2 \%$ and the thinner the thickness of the sludge, the higher the drying rate. However, it is without considering that the porosity and shape of the sludge in the dry process of the sludge, radiation intensity, the humidity and the porosity of the sludge. V. L. M athioudakis [17] studied the depth of the solar drying sludge dehydration, it is concluded that, in autumn, the content of pathogens also can meet the demands of EPA, compared with the dry conditions in summer, the final products moisture content are slightly higher than the summer, so the drying rate is also related to weather conditions.

\section{Some Innovative Developed Solar Sludge Drying System}

Whether the solar irradiation acting on the material directly or not, Solar drying plants can be divided into two categories, namely open solar dryers and cover type solar dryers. In order to maintain high drying rates and energy effectiveness, there are various types of solar dryers incorporating other combinations, such as covered a conventional heat source, heat storage devices, or heat pump. Here are some solar drying systems.

As is shown in Figure 3, the covered sludge drying device [18], the covered sludge drying plant was constructed as a tunnel type greenhouse with a roof height of $2.5 \mathrm{~m}$. It was completely enclosed by two walls, $10 \mathrm{~mm}$ thick transparent polycarbonate sheet with light transmittance of $80 \%$. Indoor air can be disturbed by a fan, which can draw the saturated wet air in the room. At the bottom of the greenhouse, there is a thermal reservoir, which absorbs heat from the hot water pipes. Under the concrete floor, a rock-bed composed of 16$48 \mathrm{~mm}$ diameter stones and $50 \mathrm{~cm}$ depth, is used as storage system. Every day and for two times, the sludge was mixed manually for sludge renewal purposes. At the application of this process, between $30 \mathrm{~kW} / \mathrm{h}$ and $2000 \mathrm{~kW} / \mathrm{h}$ to evaporate tons of water and in some cases such as chemical deodorization about $1000 \mathrm{~kW} / \mathrm{h}$ is needed.

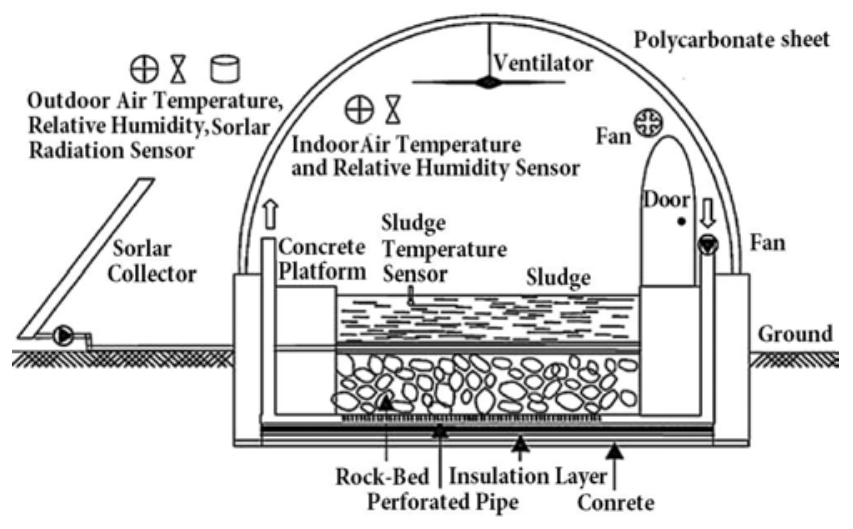

Figure 3. Schematic of the covered solar drying system.

Waste Heat of Exhaust Gas/sun capable system [19] as is shown in Figure 4.

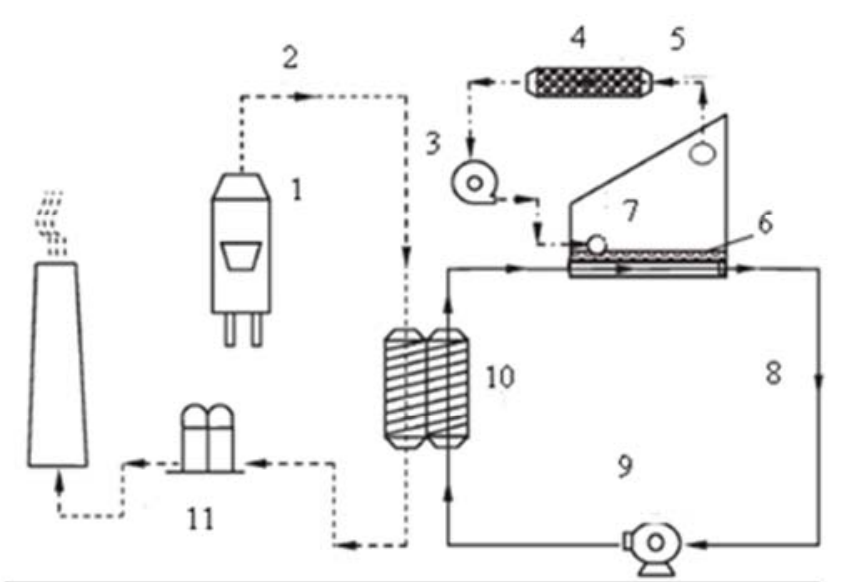

1.Boiler plant 2.Exhaust flue gas 3.Fan 4.Dehumidifying deodorizing device 5.Moist air 6.Solar / Geothermal greenhouse 7.Sludge 8.Heating oil 9.0il transfer pump 10. Heat pipe exchanger 11. Waste gas treatment

Figure 4. Power plant flue gas /waste heat, solar pre-drying system.

(1) Waste Heat of Exhaust Gas from the power plant transfer heat via heat exchanger to heat conduction oil, then the flue gas is discharged by funnel. The process not only decreases the temperature of the exhaust gas, but also preventing from air pollution. (2) Oil circulates through the 
pump, after heated up by heat exchanger, by way of the solar greenhouse of geothermal heat pipes, thereby to heat the sludge, cooled once again. Oil return to the heat exchanger to absorb of heat, which coming from the hot flue gas, flowing through the solar thermal channel heating the sludge, cooled and then returned to the heat exchanger. So during the process, the oil is heated by the exhaust gas and the sludge absorbs heat from the heated oil to dry. Because the cooled oil is also with higher temperature, the energy consumption is reduced in the circulation system. Solar greenhouse exists a good absorbance ability, the material that USES transmittance is high, make the temperature rise fast in the greenhouse, accelerate the drying rate of the sludge. Besides, Ventilation and dehumidifying equipment are added, avoiding the saturation of air humidity in the greenhouse and the foul-smelling gas produced in the process of sludge drying.

The structure and process of the solar heat pump drying system (Figure 5), which consists of a drying box, heat pump system, solar system and control system. The drying box is equipped with sludge conveyor belt for sludge input and output.

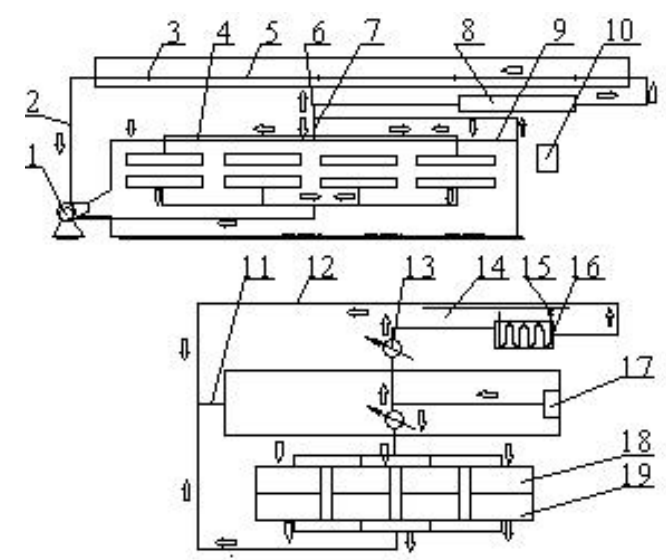

1. Fan 2. Flue pipe 3. Solar vacuum tube 4. Drying oven 5. Flue pipe 6. Offtake I 7. Oftake II 8. Intermediate water heat exchanger 9. Total exhaust pipe 10. Control cabinet 11. Total intake pipe 12. Solar tube 13. Valve 14. Reclaimed exchanger 17. Total exhaust pipe 18 . Heat pump evaporator 19. Heat pump condenser

Figure 5. Solar and heat-pump drying system.

The heat pump system [20] and the solar system are all connected by wind pipes. Air flow control valve on the wind pipe, there is air flow sensor between solar heating system and heat pump heating system. Air flow sensor and air flow control valve are connected to the controller, the controller has a temperature and humidity sensor connected to a drying oven. Air volume can be accomplished through the signal feedback of the temperature and humidity sensors and air flow sensors in the whole system. The entire drying system is closed, which can meet the environmental requirements. By running the analysis, it is concluded that consumption of per kilowatt-hour $2.5 \mathrm{~kg}$ dehydration. The system has good performance, and the requirement of moisture content and energy consumption are achieved, which can meet the actual production requirement.

Using free solar energy for sludge drying can be benefit in point of view of energy consumption and in consequence on the cost of the drying system [21-22]. Several experiment works also confirmed that solar drying plays an interesting role for the pathogen reduction of the sludge. So it is of great important significance to make full use of solar on drying products. So the author put forward a new way of thinking (Figure 6), combine with solar energy and two-phase closed thermosyphon, forming a new type of sludge drying device. Combing solar energy, with clean and renewable characteristics, with two-phase closed thermosyphon with high coefficient of heat transfer, good heat transfer, used for drying sludge, also is a promotion on technology. A study is needed about implementation of the quantification of sludge using the devices.

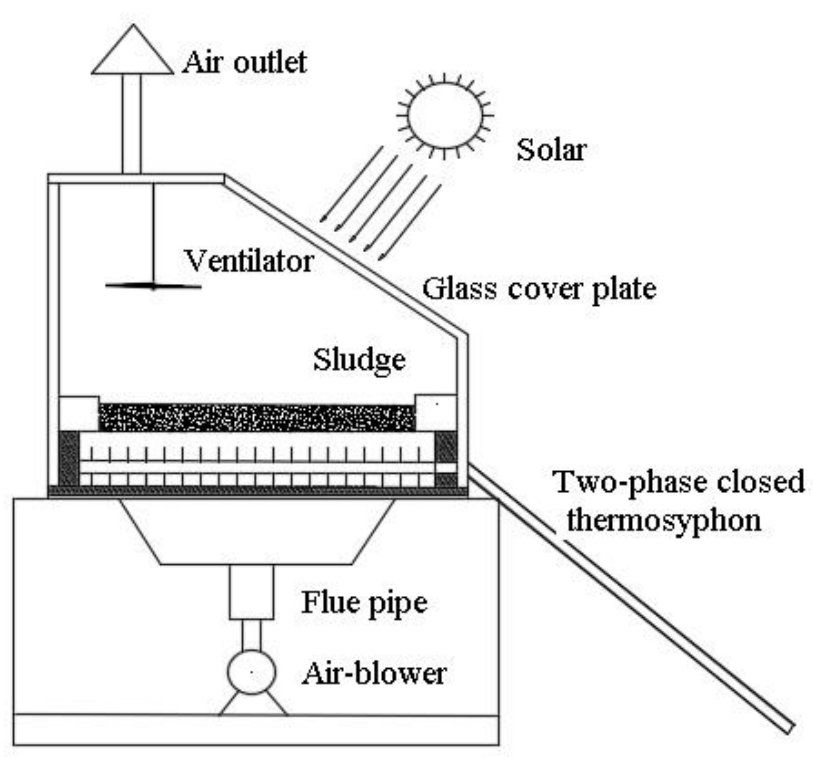

Figure 6. Solar and thermal tube drying system.

\section{Conclusion}

Drying is an essential process during the sludge management, as it reduces the quantity of sludge that could be manipulated. The general behavior of the drying kinetic during sludge drying contains a short adaptation period to the applied drying conditions. We also named the phrase as the constant drying rate period, then, one or two falling rate period followed, at last a short final period where bound water is removed. During all the drying process the product has shown shrinkage and cracks phenomena.

Using free solar energy for wastewater sludge drying can be benefit in point of view of energy consumption and in consequence on the cost of the drying system. This review has shown that in whole presented cases, sludge drying in different climatic conditions presented in their results point towards that drying is strongly affected by the air temperature, its superficial velocity, solar energy radiations 
and humidity. Several, materials were added in order to increase the efficiency of the drying systems, such as heat pump, heating the floor of the greenhouse using hot oil or adding rock-bed as thermal energy storage system. According to the obtained results and the cost of the operation, it was not benefit.

In order to respond to country's proposed sustainable development strategy, a variety of new sludge drying treatment technology has been continuously innovated and perfected in terms of safety, stability and reliability. The development direction of solar drying sludge technology is further research on using solar radiant energy, air and product temperature and humidity, which can provide a more theoretical basis for the research and development of solar drying sludge technology.

\section{References}

[1] Bennamoun L, Solar drying of wastewater sludge: a review $[\mathrm{J}]$. Renewable and Sustainable Energy Reviews, France, 2012, 1061-1073.

[2] Arlabosse P, Ferrasse JH, Lecompte D, Crine M, Dumont Y, Léonard A. "Efficient sludge thermal processing: from drying to thermal valorization [J]. vol. 4, In Modern Drying Technology: Energy Savings, France, 2012, 295-329.

[3] Tao T, Peng XF, Lee Dj, Thermal drying of wasterwater sludge: Change in drying area owing to volume shrinkage and crack development [J]. Drying Technology, China, 2005, 66982.

[4] Zheng Zonghe, NIU Baolian, LEI Haiyan, The trial of sludge dewatering and drying by solar energy $[\mathrm{J}]$. China Water and Wastewater, China, 2003, 111-113.

[5] Yuan Jun, Fan Haojie, Shi Shanbin, et al., The experimental study of sewage sludge drying fundamental characteristics $[\mathrm{J}]$. Water \& Wastewater Engineering, China, 2008, 185-188.

[6] Li Aimin, Qu Yanli, Yang Zixian, et al., Surface configuration and moisture transference during sewage sludge drying $[\mathrm{J}]$. Journal of Chemical Industry and Engineering, China, 2004, 1011-1015.

[7] Xiang YI, Liu Jianzhong, et al., The effects of solar radiation intensity on the drying properties of sludge [J]. Renewable energy, China, 2010, 715-721.

[8] Lei Z, Dezhen C, Jinlong X, Sewage sludge solar drying practice and characteristics study [J]. In Proceedings of power engineering conference, IEEE. China, 2009.
[9] Lei Haiyan, Li Weiyi, Zheng Zonghe, Experimental Study on Solar Sludge Drying [J]. Acta Energiae Solaris Sinica, China, 2004, 479-482.

[10] Wang sen, Study on solar drying and aerobic composting of municipal sludge [D]. Hebei University of Engineering, 2016.

[11] Shang Kaifeng, Liu Yanfeng, Wang Dengjia, et al. Study on the relationship between outdoor temperature and solar radiation $[\mathrm{J}]$. Civil engineering and environmental engineering, 2015(5), 116-121.

[12] Lyes Bennamoun, Patricia Arlabosse, Angélique Léonard, Review on fundamental aspect of application of drying process to wastewater sludge $[\mathrm{J}]$. Renewable and Sustainable Energy Reviews, France, 2013, 29-43.

[13] Reyes A, Eckholt M, Troncoso F, Efremov G, Drying kinetics of sludge from a wastewater treatment plant [J], Drying Technology, France, 2004, 2135-50.

[14] Léonard A, Blacher S, Marchot P, Pirard JP, Crine M, Convective drying of wastewater sludges: influence of air temperature, superficial velocity and humidity on the kinetics [J], Drying Technology, France, 2005, 1667-79.

[15] Zhang yunyue, Zhao lei, Chen dezhen, Research on the drying of sludge solar energy [J], Journal of solar energy, China, 2003, 24-26.

[16] Yin lijie, wang zhonghui, Chen dezhen, The winter solar drying experiment and process prediction [J], Journal of solar energy, China, 2013, 2088-2093.

[17] V. L. Mathioudakis, A. G. Kapagiannidis, V. I. Diamantis, A. Aivasidis, Extended Dewatering of Sewage Sludge in Solar Drying Plants [J], Science Direct, Greece, 2009, 733-739.

[18] Lyes Bennamoun, Solar drying of wastewater sludge: A review $[\mathrm{J}]$, Renewable and Sustainable Energy Reviews, Algeria, 2012, 1061-1073.

[19] LIU Hanqiao, YUAN hongmei, et al, New process of waste heat/solar pre-drying sludge $[\mathrm{J}]$, Environmental sanitation engineering, China, 2015, 13-16.

[20] Rao Binqi, Cao Li, The technology of solar and heat pump sludge drying $[\mathrm{J}]$. Journal of agricultural engineering, China, 2010, 184-188.

[21] Mayts Kurt, Aksoyt F Dilek Sanin. Evaluation of solar sludge drying alternatives by costS and area requirements [J]. Water Research, 2015, 82: 47-57.

[22] Chen Cheng, Si Dandan, Chen Qingwu, et al. Energy efficiency evaluation and adaptability analysis of solar sludge drying system [J]. Guangdong chemical industry, 2016, 43 (22): 60-62. 